\title{
UMA ESTÉTICA MAQUÍNICA
}

Rafael Andrés Villari*

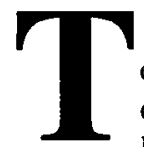

entaremos, neste despretensioso ensaio - "Ensaio: [...] gênero incerto onde a escritura rivaliza com a análise." (Barthes, 1992, p. 7) -, levantar algumas questões que repercutiram em nós no estudo da produção hipertextual, especificamente na L.G.C., quer dizer, na Literatura Gerada por Computador. Estas questōes referem-se ao estatuto da criação neste âmbito particular. Adiantamos, já que aqui não se trata de esconder as cartas, que nossa posição se tinge de certo ceticismo em relação às possibilidades levantadas por alguns autores que se enfileiram nesta corrente. Isto, sem deixar de lembrar - ao mesmo tempo - que, como diz Ernesto Sábato, um cético é um entusiasta fervoroso que, em algum momento, perdeu sua aposta. Esclarecemos também que, sendo nosso primeiro texto sobre este tema, o leitor poderá encontrar, seguramente, alguma ingenuidade na nossa crítica; por isso, nossas desculpas. Como diz Jorge Luis Borges, de quem falaremos também neste texto, "Me consta que es fácil recusar mi pobre autoridad. Espero, sin embargo, que no me prohibirán mencionar dos altos testimonios." (Borges, 1986, p. 444); neste caso, antecipamos, abusaremos do leitor apresentando três testemunhos. Diremos, também, que o acento lúdico e provocador não está ausente neste texto: uma liberdade que nos outorgamos para poder deslizar algumas dúvidas.

* Doutorando cm Literatura na Universidade Federal de Santa Catarina. 
Assim, com o intuito de levantar algumas questões, avançaremos utilizando as argumentações de um crítico e produtor reconhecido neste campo.' Neste sentido, os limites deste artigo são estreitos, na medida em que não pretende - não poderia - responder sequer a alguns aspectos deste problemático e inovador campo de construção textual, mas somente mostrar como a constituição deste tipo de trabalho - L.G.C. - reatualiza questões constantes na literatura, como as funções do autor, obra e leitor. Ao nosso ver - além do valor experimental - esse aspecto lhe outorga sua importância e destaque atual.

$\mathrm{Na}$ medida em que se trata de um campo recente, onde os conceitos e nomenclatura sofrem ainda da falta de consenso, a modo de introdução apresentaremos, através dos textos de Pedro Barbosa - como dissemos, autor que nos servirá de guia -, alguns elementos que, no dizer do mesmo, configuram "uma outra maneira de ler, uma nova maneira de escrever e de intervir sobre a palavra", onde tenta-se "abrir à literatura um novo horizonte criativo, com novas estruturas formais, oferecendo-lhe outras possibilidades expressivas ao promover uma viragem nos meios tecnológicos de suporte e de comunicação interactiva." (Barbosa, 1996, p. 20).

É importante destacar também, neste momento, que as possibilidades de produção, assinaladas pelo autor, diferem daquelas que, antes do surgimento do computador, ${ }^{2}$ eram realizadas por outros meios. Assim, o processador de texto não estaria incluído nesta gama de possibilidades de criação cibernética, embora devêssemos nos deter - em algum momento - nos efeitos que a tecnologia computacional provocou neste campo. ${ }^{3}$ Quer dizer, as possiveis mudanças

1 Trata-se de BARBOSA, Pedro. A ciberliteratura: criação literária e computador. Lisboa: Edições Cosmos, 1996, e A renovação do experimentalismo literário na literatura gerada por computador. Ciberkiosk, n. 2, maio 1998. Disponível em: http://alf.ci.uc.pt/ciberkiosk

2 Entendemos - simplificando - o computador neste campo, como a máquina que, conforme certas normas, consegue manipular grande quantidade de sinais em alta velocidade, com vantagens de rapidez e precisão.

3 No estudo desta questão encontramos mais um motivo para lamentar o fato de que Roland Barthes não tivesse acesso cotidiano a esta forma de relação com a escrita. Tratar-se-ia de ver a repercussão no estilo da produção literária, mediada pelo processador de textos, "o diálogo interativo com o ecrã faz da chamada "escrita eletrónica" uma experiência radicalmente diferente do que antes era o exercício mecânico com a máquina de escrever tradicional. [...] A escrita eletrónica coloca assim o escritor em face do ecrā numa posição dialogante e interativa com o seu próprio texto." (Barbosa, 1996, p. 31). Outro efeito - desta vez aliado à disponibilidade de informação através do computador - diz respeito ao que podemos denominar de cultura cibernética. Até há pouco tempo, quando um autor fazia, por exemplo, referência ao número de vezes ou ao local onde poderia ser encontrado tal ou qual elemento numa obra, estávamos-seguramente - frente a alguém cuja cultura e estudos the permitiam assegurar essa informação. Atualmente, com os sistemas de pesquisa disponíveis nos programas de dados, esse índice de cultura e conhecimento deve ser, no mínimo, relativizado. 
registradas na escrita daqueles que assimilaram este tipo de ferramenta. Este seria o campo do computador concebido como ferramenta.

O que nos interessa aqui é aproximar-nos da concepção que propõe o computador como elemento criativo; trata-se de analisar o novo tipo de criação estética surgida da utilização do computador, neste caso, atrelado ao campo da escrita. ${ }^{4}$ Dizemos com P. Barbosa que

Propomos assim denominar CiberLiteratura - em contraponto com a mera simulação da literatura clássica, que o computador também pode realizar - essas formas novas surgidas com o advento da informática e sem cabimento possível nos livros (do texto virtual aos geradores automáticos). A Literatura Gerada por Computador englobaria, portanto, estas duas grandes vertentes: uma atitude de "simulação" da literatura de feição clássica, na esteira do já existente, c a "ciberliteratura", abrangendo uma forma nova de produzir literatura e uma atitude exploratória de novos processos comunicativos, muitas vezes multimediáticos. A CiberLiteratura recobriria assim, na hora actual, três géneros dominantes: hipertexto, geradores automáticos $\mathrm{e}$ texto animado. (Barbosa, 1996, p. 21).

Vamos, desta forma, aproximando - conformando - um objeto textual sobre o qual podemos dirigir nosso olhar. Esse objeto textual e estético que surge da interação - necessária - do computador.

Quando um computador desenvolve e actualiza as possibilidades combinatórias, estruturais ou outras, deixadas em aberto por um determinado algoritmo potencial (como é o caso dos algoritmos combinatórios), não poderemos afirmar que a máquina cria ou, pelo menos, actualiza algo que à partida não existia? Ou que não existia senão em estado latente? E em tal caso não será legítimo apelidar tais programas de "programas criativos"? Isto é, com "potencialidades gerativas"? (Barbosa, 1996, p. 35)

4 Colocamos nesta mesma trilha de possibilidades de criação as novas tecnologias de informação que possibilitaram desde as viagens espaciais até o estudo da geometria fractal, quer dizer, campos que - em princípio - não poderiam ter surgido sem a utilizaçāo da tecnologia computacional. 
Esta concepção de criação assenta-se na idéia da não identidade entre a informação de entrada (input) e de saída (output) da máquina, como seria o caso, por exemplo, do gravador, da videocâmara ou do megafone. A questão torna-se complexa quando sabemos que não é a máquina quem produz, mas o software contido nela. Nesse ponto reencontramos uma velha figura da literatura (que chamaremos clássica em distinção à cibernética): trata-se do autor. $\mathrm{O}$ ato criativo constitui-se, assim, num processo onde intervêm dois elementos:

\begin{abstract}
O artista concebe o modelo da obra a realizar (programa), a máquina desenvolve e executa as múltiplas realizações concretas desse modelo dentro de um campo de possíveis. O texto-matriz (pattern), concebido pelo autor em estado latente ou potencial, abre-se sempre a um campo de possíveis mais ou menos vasto, e tendencialmente infinito, que constituirá o conjunto dos estados textuais actualizados ou concretos. Tal campo de possíveis dará origem a um campo de leitura, o qual pode ser explorado pelo próprio autor, que nele irá colher e seleccionar o(s) texto(s) a apresentar ao leitor, mas pode também ser explorado directamente pelo próprio leitor, dependendo isso de que use no computador o programa criado. (Barbosa, 1998)
\end{abstract}

Como podemos ver, esta concepção distancia-se das relações presentes na literatura clássica entre autor-texto-leitor: "o computador funciona, seja como um amplificador de complexidade, seja como um actualizador das capacidades textuais: quer dizer, sempre como uma prótese mental prolongando o autor duma forma simbiótica." (Barbosa, 1998)

Diziamos anteriormente, nas primeiras linhas, do nosso ceticismo aliado, é bom lembrar, a nossa pouca e recente informação ${ }^{5}$ - em relação aos efeitos de produção literária no campo da ciberliteratura. Nossa desconfiança ronda um ponto nodal: o valor estético. Entramos, desta forma, num campo dos mais escorregadios: o mesmo abrange desde o problema do cânone literário, até a própria idéia de valor na estética. De qualquer forma, mesmo que não possamos definir consensualmente a estética, podemos circular ao redor desse real - sempre problemático - que, sabemos, existe e produz, desde sempre, efeitos. Assim, dizemos que, no nosso entender, um dos aspectos principais do fato estético está atrelado ao saber que ele veicula, a

5 Embora limitada, pensamos que seja confiável. 
[a] ordem estética resgata a força tenaz da forma que continua dizendo-nos algo, pedindo uma resposta, colocando-nos a enigmática pergunta: "La música, los estados de felicidad, la mitología, las caras trabajadas por el tiempo, ciertos crepúsculos y ciertos lugares, quieren decirnos algo, $o$ algo dijeron que no hubiéramos debido perder, o estan por decir algo; esta inminencia de uma revelación, que no se produce, es, quizá, el hecho estético". (Borges, apud Arrigucci Jr., 1987, p. 234-235).

Isto parece nos assinalar que no centro do fato estético encontra-se a dimensão do enigma enquanto motor gerador de textualidade. É uma forma de fazer presente a dimensão da falta no seu caráter intransitivo e constituinte. Ou, quiçá, um ponto assintótico que nos convida ao encontro sempre adiado: "dessa perspectiva, a literatura tem o poder de se renovar sempre, sempre indagando o sentido de um enigma, cuja resposta não se pode alcançar de todo - chave perdida ou saber inacessível. Latente no seu interior, o enigma equivale a uma semente que jamais perde a força de germinação." (Arrigucci Jr., 1987, p. 235); sempre pensando que a condição estética é um encontro possível com esse saber, não como condição apriorística mas enquanto destino vislumbrado da aventura da escrita,

escritores como Sófocles, Dante e Shakespeare não se propuseram a beleza como fim, senão o exame da condição humana, a exploração dos seus abismos e limites. É claro que neste trabalho encontra-se a beleza, mas não aquela que se alcança quando se a procura por si mesma, senão outra: grande e trágica, desgarrada pela dissonância e o horror. Todas as tragédias escritas pelo homem, desde a que conta o destino de Édipo até a que narra a morte de Ivan Ylich mostram essa beleza dos abismos. (Sábato, 1981, p. 158). ${ }^{6}$

A possibilidade de produção - criativa - computacional radica numa particular concepção da arte. Trata-se de estender a concepção atomista ${ }^{7}-$ uma $^{2}$

6 O risco da tradução é nosso.

7 "no espírito não-teleológico da física jônica, as realidades fenomenais serão compreendidas como composições, agregados mais ou menos estâveis de átomos: os átomos são quantidades mínimas imperceptíveis e imutáveis das quais se formam as realidades perceptíveis e perecíveis. $\mathrm{O}$ acaso das figuras e dos movimentos provoca choques entre certos átomos, entrelaçamentos de átomos, aglomeraçōes etc., o que basta para explicar a infinita diversidade dos fenômenos." (Châtelet, 1981, p. 54) 
combinatória infinita de possibilidades entre elementos lingüísticos - à linguagem, e desta à literatura. Quer dizer, é necessário, para fazer avançar o modelo cibernético, igualar estruturalmente a linguagem à literatura. Dessa forma pode-se definir "OBRA ARTE: estrutura de signos recombinados de maneira inovadora" (Barbosa, 1998). Como sabemos, uma definição não pode coincidir - em todos seus pontos, quer dizer, igualar-se - em dois campos. A definição de P. Barbosa é, também, aplicável à linguagem. Podemos dizer que a definição de linguagem fica incluída naquela da literatura. Mas a concepção de literatura vai além, no sentido de incluir a dimensão estética como condição. No nosso entender, o elemento distintivo que define a obra de arte é seu viés estético; não coincidente, necessariamente, com seu aspecto inovador.

Curiosamente, o autor cita Jorge Luis Borges como pertencendo a um grupo de escritores que partilhariam dessa concepção - atomista - da linguagem. ${ }^{8}$ Nomear a J.L. Borges significa fazer presente um autor que antecipou em meio século as condições, hoje computacionais, da criação de textos: a possibilidade de desprender a literatura de uma combinatória de signos é tema freqüente no texto borgiano. Mas, no nosso entender, o autor argentino o faz de uma forma radicalmente diferente daquela apresentada por P. Barbosa.

Falamos anteriormente em três testemunhos; neles, pensamos que a combinatória referida associa-se, por um lado, à ordem do pesadelo - trágico e, por outro, à ironia. Encontramos isto em três textos contidos em Ficciones, publicado pela primeira vez em 1944. Reconhecemos, junto ao consenso crítico, que nestes textos a dimensão estética nos espera e assalta a cada momento de nossa experiência de leitura.

Propomos deter-nos nessas narrativas. Fizemos referência ao pesadelo, nele inscrevendo El jardín de senderos que se bifurcan e La biblioteca de Babel. Em Pierre Menard, autor del Quijote, o autor explora o determinismo combinatório, através da ironia.

8 Esta questão - a de conceder à literatura de Jorge Luis Borges uma idéia filosófica que oriente sua obra - $\hat{e}$ bastante complexa. É precisamente este aspecto que critica outro escritor, Ernesto Sábato, em Los dos Borges (p. 303) - SÁBATO, Ernesto. El escritor y sus fantasmas. In: Obra Completa: Ensayos. Buenos Aires: Seix Barral, 1996, p. 261-402. Sábato afirma que o ecletismo filosófico de J.L. Borges faz com que submeta as concepçōes filosóficas às necessidades literário-estéticas de cada momento. Acusa-o, nesse sentido, de falta de rigor filosófico. Nessa trilha, podemos dizer que J.L. Borges se utiliza das possibilidades verossímeis do atomismo para surpreender-nos com sua formulação. No horizonte de gozo de J.L. Borges sempre encontramos a figura do leitor submetido à lógica provisória e mutável. Não hesita em argumentar com metafísicas opostas e excludentes. Assim, o atomismo de Demócrito convive com o idealismo platônico; o pragmatismo com o racionalismo cartesiano. Ou, de outra forma, para Jorge Luis Borges a estética parece não ter compromisso ideológico ou filosófico. 
El jardín de senderos que se bifurcan é uma narrativa policial onde "sus lectores asistirán a la ejecución y a todos los preliminares de un crimen, cuyo propósito no ignoran pero que no comprenderán, me parece, hasta el último párrafo." (Borges, 1989, p. 429). Através desta forma narrativa-história policial - é apresentado um dos aspectos existenciais mais intrincados e recorrentes da história da filosofia ocidental: o tempo. Não entraremos nos detalhes da história - que o leitor terá, sem dúvida, presente - senão para mostrar o aspecto combinatório na determinação do porvir dos personagens. Somente lembraremos que se trata do destino de um espião - em território inimigo - cujo dever é informar sobre o local estratégico - descoberto por ele - a ser atacado; o meio imaginado para revelar - e aqui adiantamos o último parágrafo citado pelo autor - a informação: matar uma pessoa - aparecendo, desta forma, nos jornais a serem lidos e interpretados por seus superiores - homônima ao local do futuro bombardeio. No encontro dos personagens a narrativa revela a complexidade e sofisticação comum em J.L. Borges, à qual fazíamos referência. O diálogo mostra as ligações entre o assassino e sua futura vítima. Esta haveria descoberto o enigma deixado por um antepassado do espião, que teria dito, "Me retiro a escribir un libro. Y otra: Me retiro a construir un laberinto." (Borges, 1986, $\mathrm{p}$. 477); o livro - vergonha dos familiares do espião - não apresentava nenhuma coerência narrativa; ao mesmo tempo, o labirinto nunca havia sido encontrado. $\mathrm{O}$ acaso de uma carta encontrada revelara, à futura vítima, o enigma: nela lia-se "Dejo a los varios porvenires (no a todos) mi jardín de senderos que se bifurcan." (Borges, 1986, p. 477); as obras - o labirinto e o livro - coincidiam; neles, as possibilidades - virtuais - eram infinitas. Ao menos potencialmente, porque, como vimos, não se trata de porvires infinitos.

- Antes de exhumar esta carta, yo me había preguntado de qué manera un libro puede ser infinito. No conjeturé otro procedimiento que el de un volumen cíclico, circular. Un volumen cuya última página fuera idéntica a la primera, con posibilidad de continuar indefinidamente. Recordé también esa noche que está en el centro de la 1001 Noches, cuando la reina Shahrazad (por una mágica distracción del copista) se pone a referir textualmente la historia de la 1001 Noches, con riesgo de llegar otra vez a la noche en que la refiere, y asi hasta lo infinito. [...] Esas conjeturas me distrajeron; pero ninguna parecía corresponder, siquiera de un modo remoto, a los contradictórios capítulos de Ts'ui Pên. (Borges, 1986, p. 477). 
Como dizíamos, uma carta revelou o sentido do enigma; nela vislumbrase o caráter temporal do labirinto: "La relectura general de la obra confirmó esa teoría. En todas la ficciones, cada vez que un hombre se enfrenta con diversas alternativas, opta por una y elimina las otras; en la del casi inextricable Ts'ui Pên, opta - simultáneamente - por todas. Crea, así, diversos porvenires, diversos tiempos, que también proliferan y se bifurcan." (Borges, 1986, p. 478). E aqui encontramos o aspecto que nos interessa: J.L. Borges antecipa, nesta história, as possibilidades que potencialmente pensa-se poder atingir com as novas possibilidades computacionais: "Creía en infinitas series de tiempos, en una red creciente y vertiginosa de tiempos divergentes, convergentes y paralelos. Esa trama de tiempos que se aproximan, se bifurcan, se cortan o que secularmente se ignoran, abarca todas las possibilidades." (Borges, 1986, p. 479). Tratar-se-ia, assim, de uma combinatória de possibilidades aparentemente infinitas. As novas tecnologias computacionais revolucionaram as relações entre o tempo e o espaço, concretizando condições de produção a serem exploradas. Fizemos referência ao tempo, passemos agora à questão do espaço. Nesse sentido, a referência borgiana necessária parece-nos ser aquela contida no tex to La biblio-teca de Babel, onde, de outra forma, J.L. Borges nos introduz num mundo de possibilidades narrativas ordenado por uma lógica combinatória. Trata-se, apa-rentemente, de uma biblioteca que "se compone de un número indefinido, y tal vez infinito, de galerías hexagonales, com vastos pozos de ventilación en el medio, cercados por barandas bajísimas. Desde cualquier hexágono, se ven los pisos inferiores y superiores: interminablemente." (Borges, 1986, p. 465). Os livros localizam-se em "veinte anaqueles, a cinco largos anaqueles por lado, cubren todos los lados menos dos; su altura, que es la de los pisos, excede apenas la de un bibliotecario normal." (Borges, 1986, p. 465). Sobre as condições combinatórias sabemos que "cada libro es de cuatrocientas diez páginas; cada página, de cuarenta renglones; cada renglón, de unas ochenta letras de color negro." (Borges, 1986, p. 466). Acrescenta, como um dos axiomas da biblioteca, que "El número de símbolos ortográficos es veinticinco.", detalhando numa nota de pé de página - como sendo uma nota do editor - referida à frase acima, que "El manuscrito original no contiene guarismos o mayúsculas. La puntuación há sido limitada a la coma y al punto. Esos dos signos, el espacio y las veintidós letras del alfabeto son los veinticinco símbolos suficientes que enumera el desconocido."(Borges, 1986, p. 466). Estas são algumas - pensamos que as principais - condições de uma imaginária combinatória que possibilitaria a criação de textos. O fantasmagórico, quiçá sinistro, é imaginar que "De esas premisas incontrovertibles dedujo que la Biblioteca es total y que sus anaqueles registran todas las posibles combinaciones de los veintitantos símbolos ortográficos (número, aunque vastísimo, no infinito) o sea todo lo que es dable expresar: en todos los idiomas." (Borges, 1986, p. 467). Nesta biblioteca-finita 
ou infinita? - encontraríamos desde todos os clássicos até este texto que ainda - no momento da escrita e leitura - não foi finalizado: poderíamos saber seu desenlace. Ainda mais, encontraríamos os textos que ainda não escrevemos ou combinamos; poderíamos, entre outras coisas, ler aquilo que o porvir nos permitirá, ou não, combinar. Assim, a narrativa tinge-se de um sentido alucinatório e sinistro; das possibilidades, vislumbra-se o ilimitado - infinito - e ao mesmo tempo limitado, já que a combinatória teria um número possível de livros. Em repetidas ocasiões J.L. Borges retomou esta questão, ${ }^{9}$ desafiando nossas possibilidades e condições imaginativas: o finito e infinito presentes e imbricados ao mesmo tempo. Entre dois elementos, os números 1 e 2, por exemplo, um número infinito de divisões; espaço sempre passível, ad infinitum, de alcançar um elemento menor. ${ }^{10}$ Nossas possibilidades imaginativas chocamse com um real, quiçá alcançável somente pela via matemática. Podemos pensar, também, nas condições da biblioteca como regras combinatórias a serem executadas por um computador. Dissemos que em ambos os textos mencionados encontrávamos a apresentação, podemos dizer, onírica - pelo viés angustiante do pesadelo. A tentativa, também, de alcançar uma lógica outra que nos permita pensar o inimaginável. Nestes textos a questão do infinito parece assomar a cada momento, esse conceito subversivo que, no dizer do próprio Jorge Luis Borges, é uma "palabra - y después concepto - de zozobra que hemos engendrado con temeridad y que una vez consentida en un pensamiento, estalla y lo mata." (Borges, 1989, p. 248) ou de outra forma ainda, "Hay un concepto que es el corruptor y el desatinador de los otros. No hablo del Mal cuyo limitado imperio es la ética; hablo del infinito." (Borges, 1989, p. 254).

Passemos a outra forma literária de abordar a possibilidade lógica combinatória. Em Pierre Menard, autor del Quijote, o viés irônico - tão freqüente nos textos de J.L. Borges como recurso desafiante, às vezes agressivo - desprega-se a cada linha. Trata-se de um autor, Pierre Menard, o qual teria deixado uma obra inconclusa, diz o narrador: "Esa obra, tal vez la más significativa de nuestro tiempo, consta de los capítulos noveno y trigésimo octavo de la primera parte del don Quijote y de un fragmento del capítulo veintidós. Yo sé que tal afirmación parece un dislate; justificar esse 'dislate' es el objeto primordial de esta nota." (Borges, 1986, p. 446). Pierre Menard, nos conta o narrador, de maneira irônica, "No queria componer outro Quijote - lo qual es fácil - sino el Quijote. Inútil agregar que no encaró nunca una transcrición

9 Por exemplo, nos contos La perpetua carrera de Aquiles y la Tortuga (1989, p. 244-248); Avatares de la Tortuga (1989, p. 254-258); La doctrina de los Ciclos (1989, p. 385-392) e El tiempo circular (1989, p. 393-396).

10 "hay la leyenda china del cetro de los reyes de Liang, que era disminuido en una mitad por cada nuevo rey; el cetro mutilado por dinastías persiste aun." (Borges, 1989, p. 248). 
mecánica del original; no se proponía copiarlo." (Borges, 1986, p. 446). Para isto entendia que existiam dois métodos possíveis. O primeiro imaginado é aquele que concebe parte da combinatória que teria propiciado o Quixote: "El método inicial que imaginó era relativamente sencillo. Conocer bien el español, recuperar la fe católica, guerrear contra los moros o contra el turco, olvidar la historia de Europa entre los años de 1602 e de 1918, ser Miguel de Cervantes. Pierre Menard estudió esse procedimiento [...] pero lo descartó por fácil." (Borges, 1986, p. 447). Assim, "dedicó sus escrúpulos y vigilias a repetir en un idioma ajeno un libro preexistente." (Borges, 1986, p. 450). Desta forma, J.L. Borges, através desse sentido irrisório, criando um narrador que argumenta a favor do plagiário, zomba da possibilidade de reduzir o ato criativo a condições determináveis. Lembremos que, se concebemos a criação como uma lógica combinatória, devemos - levando esta condição a seus extremos - pensar também, de forma hipotética, que essa possibilidade existe.

Quiçá uma das respostas possíveis seja a de que não devamos pensar na dimensão do possível, mas do provável. Assim, encontrar o Quixote, este texto ou o próximo que escreveremos, ou El jardín de senderos que se bifurcan, numa Biblioteca possível - atualmente parece-nos que através da tecnologia computacional poderíamos saber o número de livros dessa Biblioteca, assim como também a probabilidade de encontrar um texto legível - imaginada por J.L. Borges é possível mas improvável.

Circular por alguns textos literários nos permite aproximar-nos de uma lógica criativa que, ao nosso ver, não pode ser associada a uma combinatória, na medida em que a combinação de regras determinadas não constitui a condição de produção literária; na medida em que aquilo que faz com que essas regras possam alinhavar a obra literária estaria determinado pela singularidade do desejo de quem se dispõe a escrever. E isto escapa à formalização. As narrativas de J.L. Borges testemunham este aspecto: a arte literária é uma das manifestações da subjetividade; nela, a possibilidade combinatória é a técnica a serviço de uma particularidade histórica inigualável e irreproduzível. Mesmo depois de nossa cultura ocidental ter matado - entre outros - Deus e o Autor, o sujeito da enunciação, testemunho de uma discursividade singular, continua presente na obra literária."

11 "o autor deve apagar-se ou ser apagado em proveito das formas próprias aos discursos. Entendido isto, a questão que me coloquei foi esta: o que é que esta regra do desaparecimento do escritor ou do autor permite descobrir? Permite descobrir o jogo da funçāo do autor. [... ] Definir a maneira como se exerce essa função, em que condições, em que domínio, etc., não quer dizer, convenhamos, que o autor não existe." (Foucault, 1992, p. 81). 
Devemos lembrar que estamos levando ao extremo, aos seus limites, as possibilidades assinaladas pelos entusiastas da L.G.C. Nosso objetivo, nesse sentido, é destacar o limite dessa nova tecnologia e com isto assinalar o lugar destinado à falta, à impossibilidade. Sabendo, claro, que o limite é o aspecto que nos demarca o campo de exercício da liberdade onde criar.

Porque a grande virtude da L.G.C. reside no avanço exploratório de um novo campo. Nossa - quiçá leviana - crítica aponta ao entusiasmo - em alguns casos acrítico - em que parece cair esta abordagem. Para sermos ainda um pouco mais duros, "se efectúa una suerte de deslizamiento: de la esperanza al voto, y del voto a la convicción, como si se tratara de desarrollar una fe en un dogma com la necesidad de protegerlo" (Szpirko, 1995, p. 15). ${ }^{12}$ Assim, concluindo, optamos por formalizar algumas das dúvidas que nos assaltam: porque nomear a este tipo de produção de literatura, ${ }^{13}$ com um significante tão abrangente? Alguma produção transcendeu os limites da experimentação? Esse tipo de texto deve ser valorizado como sendo produto - sabemos que em parte - do computador? Quer dizer, deve estar esse aspecto compreendido no horizonte de avaliação? Ou deve ser visado como qualquer outra produção poética? Assim, pelo dito e posicionando-nos, não concordamos quando encontramos, por exemplo, definições como a que segue:

$\mathrm{C}=\mathrm{I}(\mathrm{S}+\mathrm{R})$

Ou seja: Criar (C) no computador equivale a fornecer um repertório finito de Sinais (S), um número finito de Regras (R) para combinar esses sinais entre si, e uma Intuição (I), simulada pelo algoritmo, que determine quais os sinais e quais as regras que serão selecionados de cada vez. $O$ conjunto constitui o trinómio que define o PROGRAMA ESTÉTICO. Assinale-se que o I pode mesmo representar a intervenção do acaso como simulador da Imaginação: obtém-se então um "binómio fantástico" onde S e $\mathrm{R}$, por um lado, são a norma, enquanto I é a liberdade ou o arbítrio criativo. (Barbosa, 1998).

12 Não dispondo do texto original em francês, optamos por não traduzir estas linhas para o português apresentando-as em espanhol, para, desta forma, nāo fazer uma tradução de uma traduçāo.

13 É interessante notar que este tipo de experimentação nomina-se metonimicamente, quer dizer, utilizando o todo pela parte. A referência é à literatura quando, ao nosso ver - por enquanto - deveria restringir-se ao campo alcançado, ou seja, a forma poética. Não conhecemos romances ou dramas surgidos das possibilidades computacionais. 
Para finalizar, diremos que é contra incrédulos tradicionalistas como nós, com sua visão limitada e secular da estética, que a L.G.C. deve trabalhar e avançar. Estaremos atentos.

\title{
RESUMO
}

O trabalho pretende alinhavar questões, no nosso entender polêmicas, na teorização da produção hipertextual - neste caso limitada à Literatura Gerada por Computador: L.G.C. O questionamento aponta ao valor atribuído às possibilidades do computador no processo criativo na literatura. Utilizamos, para isto, a narrativa de Jorge Luis Borges numa tentativa de diálogo e contraste com a proposta da L.G.C.

Palavras-chave: hipertexto, estética, poesia, Jorge Luis Borges.

\begin{abstract}
This article seeks to resolve controversial issues found in hipertext production theory, in particular those associated with Computer Generated Literature (CGL). It attempts to assess the potential use of the computer in the process of literary creation. Our discussion of the CGL proposal is conducted in light of Jorge Luis Borge's narrative.

Key words: hipertext, aesthetics, poetry, Jorge Luis Borges.
\end{abstract}

\section{REFERÊNCIAS}

ARRIGUCCI JR., Davi. Epílogo. In: Enigma e Comentário: ensaios sobre literatura e experiência. São Paulo: Companhia das Letras, 1987. p. 227-235.

BARTHES, Roland. Aula. Tradução: Leila Perrone Moisés. 6. ed. São Paulo: Cultrix, 1992.

BARBOSA, Pedro. A ciberliteratura: criação literária e computador. Lisboa: Cosmos, 1996. 
A renovação do experimentalismo literário na literatura gerada por computador. Ciberkiosk, n. 2, maio de 1998. <http://alf.ci.uc.pv/ciberkiosk>.

BORGES, Jorge Luis. Obras Completas. 1923-1972. 17. ed. Buenos Aires: Emecé, 1989. CHÂTELET, François. História da filosofía: idéias e doutrinas. A filosofia pagã. Traduçāo: Maria José de Almeida. Rio de Janeiro: Zahar Editores, 1981.

FOUCAULT, Michel. O que é um autor? Lisboa: Vega, 1992.

SÁBATO, Ernesto. El escritor y sus fantasmas. 2. ed. Madrid: Seix Barral, 1981.

SZPIRKO, Jean. La clínica psicoanalítica ... com el correr de la ciencia. Tradução: Pura H. Cancina. Rosario: Homo Sapiens, 1995. 